\title{
It's the junk that makes us human
}

Anyone who has ever put together self-assembly furniture knows that having the right parts is important, but what you do with them can make or break the project. The same seems to be true of the vast amounts of DNA in an organism's genome that used to be labelled as junk. Studies now indicate that this DNA may be responsible for the signals that were crucial for human evolution, directing the various components of our genome to work differently from the way they do in other organisms.

The findings seem to bolster a 30 -year-old hypothesis that gene regulation - not the creation of new genes - has moulded the traits that make us unique.

The latest work looks for regions of the genome that have changed rapidly in human evolution, based on the theory that they are most likely to have shaped our differences from other animals. But instead of hunting for rapidly evolving DNA in genes, researchers are starting to look at non-coding DNA stretches of DNA that don't encode proteins.

In a paper published in Science on 3 November, for example, a group led by Edward Rubin of the Lawrence Berkeley National Laboratory (LBNL) in Berkeley, California, reports the result of one hunt through the non-coding genome $^{1}$. The team defined a group of 110,549 regions of non-coding DNA that are largely

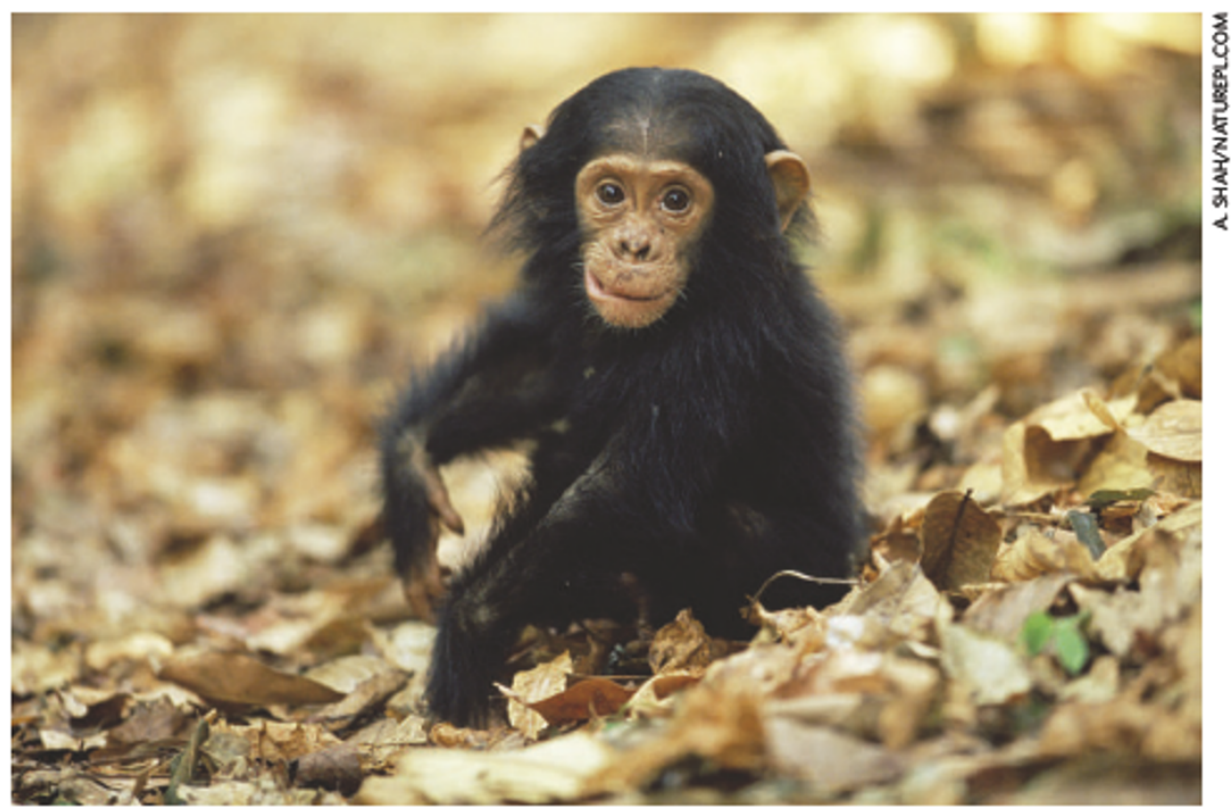

It's all relative: could non-coding DNA be an important factor that separates chimps from humans?

the same in humans and other mammals, reasoning that these regions must be important or they would have changed by randomly mutating over time. The researchers then narrowed the list to 992 regions that have changed markedly in humans compared with other mammals. Finally, they asked, if these pieces of DNA are regulators, what biological functions do they control?

They found that these stretches of non-coding DNA tend to lie near genes involved in brain-cell function - specifically, in building

\section{Faculty forces president to quit Swiss role}

One of Europe's star universities nosedived into crisis last week when its faculty members forced the president to resign.

Molecular biologist Ernst Hafen, who took over the reins at the Swiss Federal Institute of Technology (ETH) in Zurich last December, submitted his resignation letter on 1 November, a day before a planned faculty vote of confidence he was certain to lose. "It has become clear over the past few days that I don't have the necessary support to continue," Hafen said in a statement.

Hafen had been mandated to reform the ETH by its supervisory council. But his style and his plans both angered and failed to convince senior professors, who banded together to demand that he go.

Hafen is not the first ETH president to have been forced out - there was a quiet resignation in the late 1980 s. But the university, which trumpeted its 150 th anniversary last year, has never experienced such hostile internal turmoil.

The ETH came out as the top-performing university in mainland Europe and 27th in the world in the University of Shanghai's 2006 world ranking of universities. It claims 21 Nobel prizewinners, starting with the first laureate, Wilhelm Röntgen, in 1901. Alexander Zehnder, president of the ETH Council, had even greater ambitions: he wanted to raise the university into the top ten worldwide, and asked Hafen to make organizational changes to that end.

Hafen, a highly regarded researcher with a strong publication record, had been considered by the ETH Council - a body nominated for five-year periods by the Swiss federal government - as an ideal candidate to do this. At 50, he was still young. He had experience in setting up a biotech company, The Genetics Company, and he worked in a research area - systems biology - that is a Swiss priority. Hafen is one of the co-developers of Systems $\mathrm{X}$, the prestigious Swiss national systems-biology network.

Former scientific colleagues refer to Hafen as warm and collegial. But ETH faculty members were clearly not seduced, claiming that his challenges to all aspects of their work encroached on their traditional autonomy. They said that his plans for a rapid reform of the university, a programme known internally as ETH 2020, were ill conceived - and that Hafen often failed to explain which problems they were designed to solve, and how they would solve them. Worse still, critics say, Hafen set up a consultation procedure but then ignored their own carefully formulated input. Attacks on Hafen by some faculty members reportedly became personal.

Key reforms included abolishing the 
